\title{
ANGIOFIBROMA NASAL JUVENIL CON IMPORTANTE AFECTACIÓN LOCORREGIONAL
}

\section{JUVENILE NASAL ANGIOFIBROMA SIGNIFICANT LOCOREGIONAL INVOLVEMENT}

\section{ANGIOFIBROMA NASAL JUVENIL ENVOLVIMENTO LOCORREGIONAL SIGNIFICATIVO}

\author{
Juan Ramón y Cajal Calvo ${ }^{1,3}$, Carlota Maria Bello Franco ${ }^{1}$, Pablo Vela Gajón ${ }^{2}$, María José Gimeno Peribañez ${ }^{1}$, Gloria Tejero \\ Garcés Galve².
}

El angiofibroma nasal juvenil es un tumor benigno localizado en las fosas nasales que afecta casi exclusivamente a adolescentes del sexo masculino. La clínica que presenta fundamentalmente es sangrado por las fosas nasales y sensación de obstrucción nasal. Para su diagnóstico es importante una correcta exploración física y también la realización de pruebas de imagen radiológicas. A pesar de tratarse de una patología de buen pronóstico, es necesario su extirpación quirúrgica debido al posible crecimiento de la lesión que pueda implicar problemas de mayor gravedad al afectar a estructurar próximas como pueden ser los globo oculares o ciertas zonas del cerebro.

\section{Conceptos clave:}

Que conocemos del tema: El angiofibroma nasal juvenil es una neoplasia de carácter benigno propia de la población adolescente. Se manifiesta principalmente como obstrucción nasal y epistaxis; sin embargo, puede ocasionar otros síntomas dependiendo del tamaño y de la extensión tumoral. Las técnicas de imagen (TC, RM ), son fundamentales para su diagnóstico. Debido a su comportamiento hipervascular y tendencia al sangrado se realiza una embolización de la lesión previa a la cirugía de resección.

Aportes: Se presenta el caso de un paciente con clínica característica sugestiva de angiofibroma nasal juvenil. Las imágenes tanto de la tomografía computarizada como las de la resonancia magnética cerebral muestran un patrón característico de esta lesión, con realce vascular tras la administración de contraste intravenoso que además ponen de manifiesto una importante afectación locorregional con infiltración del seno maxilar e invasión infratemporal poco frecuente.

1. Servicio de Radiodiagnóstico. Hospital Clínico Universitario Lozano Blesa. Zaragoza. España

2. Servicio de Otorrinolaringología. Hospital Clínico Universitario Lozano Blesa. Zaragoza. España

3. E-mail de contacto: jramonycajalc@gmail.com

\section{Resumen}

El angiofibroma nasal juvenil es un tumor de carácter benigno, caracterizado por la vascularización abundante y tendencia a la hemorragia. A pesar de su histología benigna, puede presentar un crecimiento localmente expansivo que suele presentar una remodelación ósea y efecto masa de estructuras adyacentes. Se presenta el caso de un paciente de 15 años de edad, que acude al servicio de urgencias de nuestro centro por epistaxis de repetición. Tras la exploración física se deciden realizar pruebas de imagen (TC y RM) que ponen de manifiesto la presencia de una gran masa hipervascular en la fosa nasal derecha y seno maxilar. El paciente es intervenido quirurgícamente previa embolización del tumor.

Palabras clave: epistaxis; angiofibroma; nasofaringe.

\section{Abstract:}

Juvenile nasal angiofibroma is a benign tumor characterized by abundant vascularization and a tendency to hemorrhage. Despite its benign histology, it can present locally expensive growth that usually presents bone remodeling and the mass effect of adjacent stuctures. We present the case of a 15-year-old patient who came to the emergency department of our center for recurrent epistaxis. After physical examination, it was decided to carry out imaging tests (CT an MRI) that reveal the presence of a large hypervascular mass in the right nostril and maxillary sinus. The patient undergoes surgery after embolization of the tumor.

Keywords: epistaxis; angiofibroma; nasopharynx.

\section{Resumo}

O angiofibroma nasal juvenil é um tumor benigno, caracterizado por vascularização abundante e tendência a hemorragia. Apesar de sua histologia benigna, pode apresentar crescimento localmente expansivo que geralmente apresenta remodelação óssea e efeito de massa de estruturas adjacentes. Apresentamos o caso de um paciente de 15 anos de idade que veio ao pronto-socorro de nosso centro por epistaxe recorrente. Após o exame físico, optou-se pela realização de exames de imagem (TC e RM) que revelassem a presença de grande massa hipervascular na narina direita e seio maxilar. O paciente é submetido à cirurgia após embolização do tumor.

Palavras-chave: epistaxe; angiofibroma; nasofaringe.

Recibido: 2020-05-11 Aceptado: 2020-06-10

DOI: http://dx.doi.org/10.31053/1853.0605.v78.n1.28538 
El angiofibroma nasofaríngeo juvenil es una tumoración que representa alrededor del $0,05-0,5 \%$ de los tumores de cabeza y cuello y es considerado la más común de las neoplasias benignas de la nasofaringe. De histología benigna, su localización habitual se origina en la mayoría de los en el margen superior del foramen esfenopalatino con extensión hacia fosa pterigopalatina. ${ }^{1,2}$

Se presenta un paciente de 15 años de edad, que acude al servicio de urgencias de nuestro centro por epistaxis de repetición diaria de aproximadamente 4 meses de evolución, que cede con la compresión manual, acompañado de hiposmia y disgeusia.

Se le practica una fibroscopia de urgencia donde se objetiva una lesión polipoidea y fibrosa con aspecto de angiofibroma que ocupa la fosa nasal derecha desde el área III hasta el cavum. Por este motivo, al paciente se le realiza de urgencia una TC y RM de fosas nasales, senos paranasales y nasofaringe, con contraste, (figuras 1 y 2 ) para delimitar con exactitud la extensión de la lesión.
Los hallazgos de imagen demuestran la presencia de una gran masa hipervascular que presenta captación de contraste en fosa nasal derecha y nasofarínge que destruye las paredes medial y posterolateral del seno maxilar derecho con infiltración del mismo, con ensanchamiento de la fosa pterigopalatina e invasión infratemporal y extensión a celdillas etmoidales y seno esfenoidal (asteriscos en figuras).

Los datos clínicos y radiológicos son compatibles con el diagnóstico de angiofibroma nasal juvenil de gran tamaño. Su tratamiento consiste en la extirpación quirúrgica previa embolización de la lesión ${ }^{3}$.

\section{Imágenes}

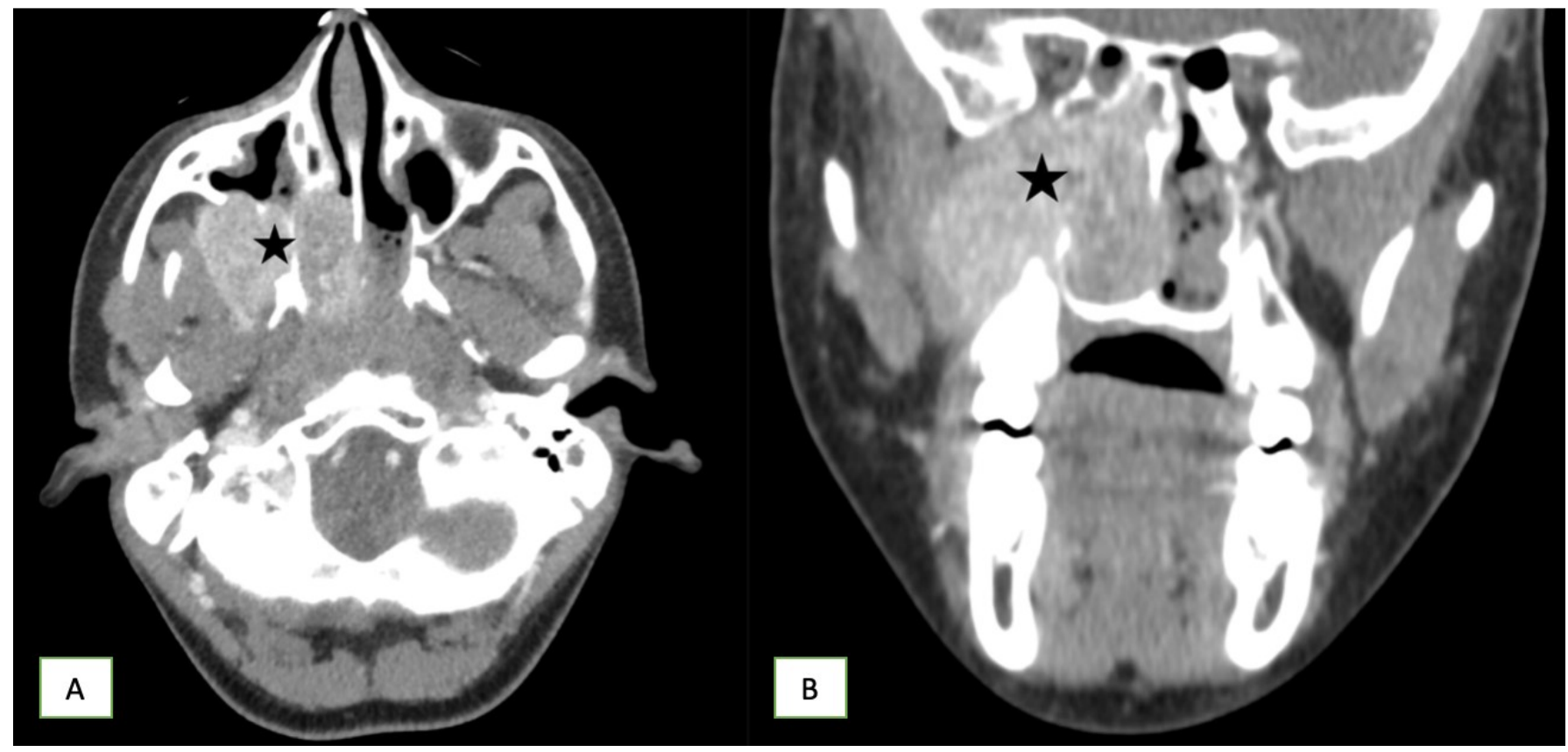

Figura $N^{\circ}$ 1. Imágenes TC corte axial (A) y corte coronal con contraste intravenoso (B). Se visualiza una masa hipervascular en fosa nasal derecha que destruye paredes medial y posterolateral de seno maxilar derecho con infiltración del mismo, e invasión infratemporal. Asímismo, se observa extensión a celdillas etmoidales y seno esfenoidal con destrucción parcial de la hendidura pterigomaxilar. (asteriscos). 


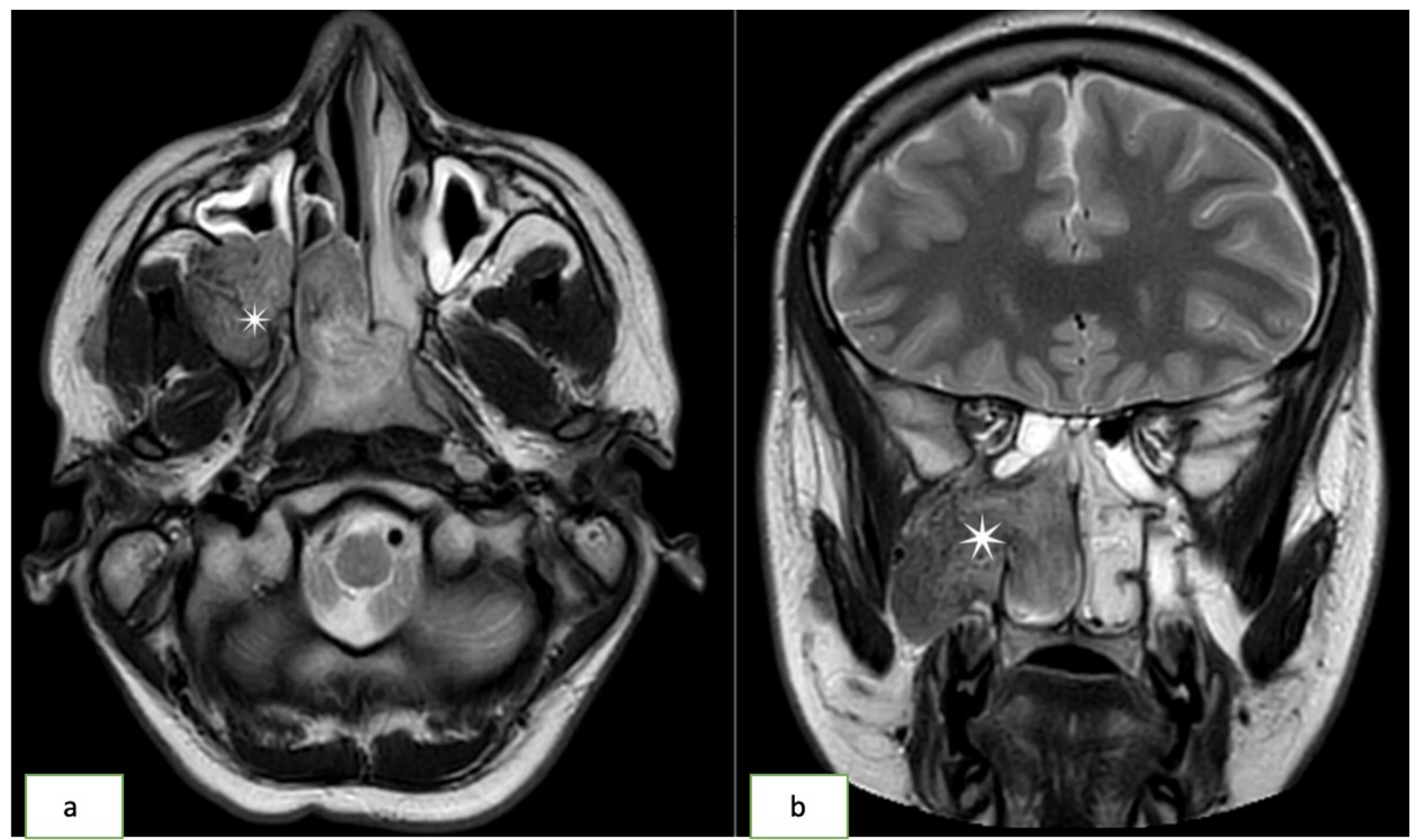

Figura 2. Imágenes RM secuencias ponderadas en T2 cortes axiales (a) y coronal (b)

Se visualiza una voluminosa masa localizada a nivel de fosa nasal derecha, que se extiende a seno maxilar derecho, con ocupación prácticamente completa del mismo y extensión a fosa pterigopalatina (asteriscos).

La citada masa presenta una intensidad de señal intermedia, con áreas en vacío de señal a nivel de la misma, y que tras la administración de contraste paramagnético muestra un claro realce asociado.

Limitaciones de responsabilidad:

No responsabilidad del Hospital Clínico Universitario Lozano Blesa o del Sistema Aragonés de Salud en el estudio.

En todo momento, se ha mantenido la confidencialidad de los pacientes, ya que solo el autor principal ha tenido acceso a los datos para poder obtener la información iconográfica, previa autorización por parte de la Dirección del hospital.

Fuentes de apoyo:

No intervención de empresas externas en el proyecto. No subvenciones u otras fuentes de apoyo

\section{Originalidad:}

Este trabajo ha sido enviado exclusivamente a la Revista de la Facultad de Ciencias Médicas de Córdoba, y no se utiliza en él ningún material proveniente de ninguna publicación previa.

\section{Responsabilidad y participación de los autores:}

Todos Cumpliendo con las categorías generales del ICMJE, han participado en los diferentes apartados que se indican a continuación:

Responsable de la integridad del estudio.

1. Concepción del estudio.

2. Diseño del estudio.

3. Búsqueda bibliográfica

4. Redacción del trabajo.

5. Revisión crítica del manuscrito con aportaciones intelectualmente relevantes.

6. Aprobación de la versión final.

\section{Cesión de derechos:}

Los autores ceden el derecho de autor a la Universidad Nacional de Córdoba para publicar en la RFCM y realizar la traducción en inglés.

\section{Conflicto de interés:}

No existen conflictos de intereses que declarar, ni financiación económica.

\section{Bibliografía}

1. Hunt $\mathrm{CH}$, Morris JM, Lee PU, Cloft $\mathrm{H}$. Progressive epistaxis in two young males: Classic presentations of juvenile nasopharyngeal angiofibroma in unusual locations. Neuroradiology. 2010 May;52(5):419-20. doi: 10.1007/s00234-010-0656-y.

2.Ballah D, Rabinowitz D, Vossough A, Rickert S, Dunham B, Kazahaya K, Cahill AM. Preoperative angiography and external carotid artery embolization of juvenile nasopharyngeal angiofibromas in a tertiary referral paediatric centre. Clin Radiol. 2013 Nov;68(11):1097-106. doi: 10.1016/..crad.2013.05.092.

3. Hyun DW, Ryu JH, Kim YS, Kim KB, Kim WS, Kim CH, Yoon JH. Treatment outcomes of juvenile nasopharyngeal angiofibroma according to surgical approach. Int J Pediatr Otorhinolaryngol. 2011 Jan;75(1):69-73. doi: 10.1016/j.ijporl.2010.10.010. 